\title{
Polysemous Words in English Movies, Learning Obstacles or Gifted Talent?
}

\author{
Lee, Yun Joon Jason ${ }^{1}$
}

\begin{abstract}
The purpose of this paper is twofold: (1) to investigate how L2 learners deal with polysemous words or phrases without instruction about polysemy and (2) to observe what alternatives L2 learners have instead of instruction. In this paper, a case study was administered with three advanced college students. The material was an American movie, Café Society (Allen, 2016). All participants were tested three times with mostly polysemous words and phrases. It was found in the first test that the participants depended heavily on context to decide which senses of polysemous words were appropriate. The second test showed that the participants failed to handle the context because it was too difficult for them. In the third test, participants often misjudged the context and consequently made wrong choices among several senses. The results of the tests indicate that context is key to dealing with polysemous words or phrases. The pedagogical implication is that L2 students need context to deal with polysemous words or phrases. Teachers must instruct about the context. Image schemas and conceptual metaphors are only products of the interaction between context and polysemous words.
\end{abstract}

Keywords: polysemy, context, image schema, conceptual metaphor, cognitive linguistics Applicable level: college

\footnotetext{
${ }^{1}$ Corresponding author, Associate professor, Dept. of English Education, Daegu National University of Education, Sangrok Education Center \#501, 219 Jungang-daero, Nam-gu, Daegu City, 42411, Korea (E-mail: jlee@dnue.ac.kr)

Received: October 15, 2021

Revised: November 17, 2021

Accepted: November 21, 2021

Copyright: (C) 2021 The Society for Teaching English through Media (STEM)

This is an open access article distributed under the terms of the Creative Commons Attribution Non-Commercial License (http://creativecommons.org/licenses/by-nc/4.0), which permits unrestricted non-commercial use, distribution, and reproduction in any medium, provided the original work is properly cited.
} 


\section{INTRODUCTION}

Traditionally, it has been believed that language consists only of grammar (primary) and vocabulary (secondary). However, Willis (1990) argued that words and grammar should be treated equally. Lewis (1993) also emphasized that vocabulary and grammar should be merged. Selivan $(2018$, p. 1) suggested that classroom activities are "making grammar teaching more lexical and [...] making vocabulary practice more grammatical." Since then, the status of vocabulary has been raised in language-relevant fields, and it is central to language teaching. Therefore, it is no wonder that building a sizable vocabulary is essential to L2 learners.

The current literature mentions that polysemy ${ }^{1}$ is an obstacle to sizable vocabulary (Boers, 2013; Csábi, 2004; Makni, 2014; Veliz, 2018). To understand this phenomenon, researchers have imported insights from cognitive linguistics, including image schemas and conceptual metaphors (Makni, 2014). Along with this tendency, English as a Foreign Language (EFL) classrooms have demonstrated the effectiveness of applying image schemas and conceptual metaphors to polysemous words (Abou-Khalil, Helou, Flanagan, Chen, \& Ogata, 2019; Csábi, 2004; Veliz, 2018; Wei \& Lou, 2015).

Meanwhile, some literature has agreed to disagree with current studies. Ullmann (1959) expressed gratitude for polysemous words. It is true that we cannot talk without them. Falkum $(2009,2011,2015)$ has expressed a more changing voice against current research. She has said that polysemy has few problems in conversation. She has continued to claim that the problem comes from the theoretical and descriptive work of polysemy. In general, EFL classrooms cannot be the center of linguistic research practice. As far as communication flows without problems, it cannot be accepted that polysemy is treated with image schemas and conceptual metaphors in the classroom.

In fact, language grows in context (Rowe \& Weisleder, 2020). Early word learning occurs across different contexts (Goldenberg, 2015). Hoff (2006) also mentioned that context-that is, all human environments-helps language learning. Then, we can assume that L2 learners may figure out appropriate senses of polysemous words, depending on the context. According to cognitive grammar, L2 learners can obtain the meaning of an expression from a situational context (Taylor, 2002).

This paper investigates how L2 learners deal with polysemous words or phrases without receiving any instruction on polysemy. A particular movie text was chosen for the analysis because it is full of polysemous words and has a rich context for guessing and inferencing. This paper aims to observe what can help L2 learners manage to handle polysemous words without any help. EFL teachers may have different attitudes about polysemy if the results of the experiment reveal that $\mathrm{L} 2$ learners can handle polysemous words or phrases without any complicated instruction on image schemas and conceptual metaphors. If you have polysemous words in the mental lexicon, you can communicate with ease because you use the same language form to express different meanings. As a listener, you also listen to the other interlocutor with much less energy. This is because you can listen to one language form for different meanings; polysemous words make conversation easier for memorizing huge vocabulary.

\section{LITERATURE REVIEW}

\section{What Is Polysemy?}

Research into polysemy is said to have begun in the late $19^{\text {th }}$ century (Nerlich, 2003), and it blossomed in the 1980s. Metaphor we live by (Lakoff \& Johnson, 1980), which was published during this period, became a standard text for researchers who were interested in cognitive semantics (Nerlich, 2003). Since metaphor comprehension and polysemy were deeply related, this period was regarded as the full-fledged time to study polysemy (Tremblay, Macoir, Langlois, \& Monetta, 2014).

The problem is that polysemy is tough to define. Some literature has said that a clear distinction between polysemy and homonymy is vital to understand polysemy (Daiu, 2015; Faniran, 2016). If polysemy is not properly defined,

\footnotetext{
${ }^{1}$ A widely accepted definition of polysemy is that "the form of ambiguity where 2+ related senses are associated with the same word" (Gries, 2015, p. 472).
} 
people may be confused due to homonymy. Distinction between polysemy and ambiguity can be another factor in understanding what polysemy is (Sennet, 2016). The following examples are from Sennet (2016).

Dusko wants to buy a big dog treat.

The above sentence is evidently polysemous in that the phrase a big dog treat has two distinct meanings.

Dusko wants to buy a dog treat that is large.

Dusko wants to buy a treat appropriate for large dogs.

We do not need to explain the differences between the two sentences in detail. The important point to note is what makes the sentences polysemous. Syntactic ambiguity generates polysemous sentences in the phrase big dog treat. There are two different phrases that look alike. Not only lexical polysemy but also syntactic polysemy might confuse language users. However, if you keep in mind that syntactic phrases cause ambiguity, nothing confusing has happened. Now, let us focus more on lexical polysemy. One of the features of polysemy is the relationship between it and some core meanings. Lakoff (1987, p. 316) discussed this:

Polysemy occurs when a single word has more than one meaning and when those meanings are systematically related. A systematic relationship is crucial here. The two meanings of bank-a place where you put your money or the edge of a river-are not systematically related. Such cases are called homonyms. Cases of polysemy are cases like warm, which refers both to the temperature and to clothing that makes you feel warm.

Gries (2015, p. 472) also provided the same idea as Lakoff. He mentioned that polysemy is a form of ambiguity because a word includes at least two meanings, and they are related to each other. He continued to give example sentences for ambiguity, as follows:

I emptied the glass ('container').

I drank a glass ('contents of the container').

In the first sentence, glass is a container; in the second sentence, glass refers to contents. They are totally different things. Though they reflect a high degree of ambiguity, they are polysemous. Nobody is confused by such ambiguity or different senses.

So far, polysemy seems to be described intricately, but Kovács (2011) presented a positive remark about it. He said that polysemy is a concept that reflects the economy of language. He mentioned that polysemy is "a necessary means of language economy" (p. 3). Ullmann (1959) also stated that polysemy is an essential resource of language economy. Ravin and Leacock (2000) remarked that L2 learners can choose appropriate senses of polysemous words without difficulty. Some literature has mentioned that polysemy is not a problem in real communication (Falkum, 2009, 2011, 2015; Kovács, 2011).

\section{Example Cases of Teaching Polysemous Words}

In most teaching fields, it is a headache to teach vocabulary due to the ambiguous properties of polysemy. To overcome this difficulty, insights from cognitive linguistics, such as image schemas and conceptual metaphors, have been used in the classrooms. This tendency may be because polysemy is a core area of linguistic semantics in cognitive linguistics (Cuyckens \& Zawada, 1997).

Littlemore (2009) has published Applying cognitive linguistics to second language learning and teaching and emphasized the relation between cognitive linguistics and second language learning. Regarding polysemy, Littlemore (2009, p. 7) said the following: 
[...] the various senses of particular words are also viewed as radial categories, with the more concrete, physical senses lying towards the centre of the category and the more abstract, metaphorical senses lying towards the periphery. The different senses are thought to be related through metaphor and metonymy. I explore the implications that this has for language learning and teaching.

According to her, different senses of polysemous words are connected from the physical senses to the abstract senses. Image schemas and conceptual metaphors play certain roles in this flow. English as a Second Language (ESL) or EFL classrooms tend to use such ideas with students. The following accounts for some cases of this.

Mitsugi (2013) taught 99 Japanese college learners of English the temporal use of the English prepositions: in, on, $a t$, and $b y$. Two different types of instruction were used: core meaning-based instruction (CMBI) and translationbased instruction (TBI). The results showed that CMBI was significantly more effective than TBI in the upper-and lower-score groups. This experiment suggested that CMBI should proceed with explicit instruction. It also indicated that CMBI worked well for lower-proficiency learners. Makni (2014) used image schemas to teach polysemous vocabulary, incorporating two methods. One was the image schema-based vocabulary instruction method (ISBM), and the other was the translation-based vocabulary instruction method (TBM). The results showed that ISBM was much better than TBM for remembering vocabulary. Mitsugi (2017) conducted a similar experiment to Mitsugi (2013). The participants were 88 Japanese English-major college freshmen. Mitsugi taught polysemous English prepositions (at, in, on) using two different methods: schema-based instruction (SBI) and TBI. The results showed that SBI was more effective than TBI. However, a different discovery from Mitsugi (2013) was that SBI was practical for teaching students. Another discovery was that the necessity of both methods depended on the learning situation. Vardidze (2020) used a similarity-based approach (SBA) to teach English polysemous words for $6^{\text {th }}$ grade Georgian students of a public school. He believed that even younger children who have a good memory of language acquisition often fail to memorize polysemous words successfully. SBA refers to an image-schema-based approach. This approach aims to make students aware of both the core meaning of a word and the extended meaning of the word. The results showed that SBA participants remembered vocabulary better than traditional methods.

From these experiments, we can observe that each study used translation methods for the control group, indicating that translation methods are regarded as old-fashioned. Each study should have an explicit or implicit way to teach polysemous words, or it should have compared image-schema-based methods with context-based methods. This leaves much to be desired.

\section{Challenging Issues}

This section raises two issues. The first question: who is interested in polysemy and whether they are linguists or L2 learners. Polysemy is mainly concerned with lexical semanticists and lexicographers (Kovács, 2013). Falkum and Vicente (2015) also mentioned that polysemy rarely causes any difficulty for speakers and that it has proved difficult to treat theoretically. Though Langacker $(1987,1988)$ made a strong claim of psychological reality against current linguistic descriptions, he cannot deny that he is stuck in his profession. Literature in this field has argued that polysemy is a complex linguistic phenomenon (Daiu, 2015; Jager \& Cleland, 2016; Vicente \& Falkum, 2017). Such studies are all focused on linguistic questions and answers, not on real life, which can be an important key in second language learning. It should be kept in mind that most EFL learners are ignorant of the concept of 'polysemy' and that they might be indifferent to learning the core and extended meanings of vocabulary. Academic societies mainly agree on the effectiveness of polysemous vocabulary teaching based on cognitive semantics, including image schemas (Bielak, 2011; Evans \& Tyler, 2005; Holme, 2012; Matsumoto, 2006; Tyler, Mueller, \& Ho, 2011). Their achievements should not be blamed. However, EFL classrooms may differ from academic environments in a broad sense. The former should be more sensitive to 'naturalness' than the latter. Simply put, polysemy is a natural phenomenon, not a linguistic phenomenon.

The second issue concerns how we can deal with polysemous words for L2 learners by using insights from cognitive linguistics or by simply using context. Gries (2015) mentioned that we should recognize the importance of context in understanding polysemy and that linguistic and encyclopedic knowledge work together. The next passage reflects why context is more important than linguistic achievements, such as image schemas and conceptual 
metaphors.

Of special importance is the fact that polysemy exists only in language, not in speech. The meaning of a word in speech is contextual. Polysemy does not interfere with the communicative function of a language because in every particular case the situation or context, i.e. the environment of the word, cancels all the unnecessary meanings and makes speech unambiguous ("Polysemy and context," n.d.).

The first sentence says that polysemy exists only in language, not in speech. Language is related to linguists, but speech is related to L2 learners. Since context can take care of polysemous words, teachers should cautiously consider whether they import ideas of cognitive linguistics into their classrooms.

Therefore, EFL teachers should ask themselves questions, as polysemy is said to be pervasive in natural languages. Possible questions include: why does this happen, and why does every language have a polysemy phenomenon? The answers may be short and simple. Language users need polysemy. As Ullmann (1959) noted that you cannot talk without polysemy. If polysemy did not exist, language users would die in the middle of learning new, proper words for unlimited situations.

Polysemy is a natural phenomenon that helps language users to express many words with small vocabulary, which means that humans innately maintain the properties of polysemy. Linguists explicitly expose polysemy, and their efforts to understand humans should be admired. However, for L2 teaching and learning, we should be meticulous because the use of polysemy in ESL or EFL classrooms is only just beginning (Littlemore \& Juchem-Grundmann, 2010; Veliz, 2018). Polysemy is also a diverse phenomenon, so we can see only a small aspect of it. Therefore, we cannot expect a general overview of polysemy yet.

\section{DESIGN}

\section{Goal}

The goal of this experiment is twofold: (1) to investigate how participants handle polysemous words in English movies. Specifically speaking, it is to observe where participants get source information to decipher the correct meanings of polysemous words. It is expected that they refer to dictionaries (bilingual, mono dictionary, or other dictionary-type sources), context in texts, or native speakers. The aim is also (2) to determine whether participants consider polysemous words as learning obstacles. Participants' feelings of difficulty or having a headache to choose the correct senses of polysemous words (are) investigated (through tests). The results will foreshow how polysemous words will help the ESL teachers in understanding the learners.

\section{Participants}

This is a case study, and three English-major college students participated in the activity. This experiment required high-intermediate or advanced students-as handling polysemous words is not an easy task. The TOEIC scores of the participants were all between 850 and 900 . They are called A, B, and C. Participant A had worked for almost one year in Europe, and participant B had been at an international language school for about one year in the United States. Participant $\mathrm{C}$ had never been overseas but had experienced English learning through watching movies for several years. Participants A and B had never watched movies for their English learning.

\section{Text Material}

The material used in this experiment is Café Society (Allen, 2016), which is a 2016 American romantic comedydrama film written and directed by Woody Allen. There are two reasons for choosing this movie as a text material: emotion and context. Words expressing emotions deliver specific and rich contexts, resulting in lexical ambiguity, such as polysemy (Ki \& Shin, 2020). In this movie, emotions are up and down among characters, as in other movies. 
For example, two main characters-Bobby and Veronica-happen to fall in love, but it does not last as they marry different people, causing emotional intensity to surround them. Bobby's elder sister, Evelyn, marries Leonard-who is a professor majoring in philosophy. They are intelligent people but tend to argue with each other, depending on the agenda, and sometimes burst out emotionally. Bobby's mother and father, Rose and Marty, constantly quarrel. It is expected that this movie will have many polysemous words and phrases.

Another reason to use movies, including Café Society, is context. According to Kovács (2013, p. 62), "word meaning is the result of contextual specification." Some literature also mentions that context has an effect on the nature of polysemy (e.g., Croft \& Cruse, 2004; Evans \& Green, 2006). Since this case study observes the relationship between polysemy and context, this movie is appropriate as a text here. Of course, it should be admitted that every movie usually includes emotion and a rich context. In Café Society, emotional disturbance and context are easily shown.

\section{Procedure and Evaluation}

The procedure is rather straightforward. The students study the transcripts of the movie, because all three participants are high-intermediate level in English, they require minimum help from the teacher. The teacher's role is to observe the students and decide the scenes to be tested. Additionally, the teacher will determine what to teach based on the test results of the participants. The main role of the teacher in this study is to mark the errors of words or phrases and implicate them in the upcoming tests.

The test will be done in three phases. Each test should be based on the errors committed by the participants. Thus the first test had 9 words and phrases while second test had 7, and the last test had 6. Not all words given in tests are polysemous words. In addition, several polysemous words are extension of basic meanings or several meanings. Further explanation will be given in the next chapter.

\section{RESULTS AND ANALYSIS}

Before analyzing the results, some explanations for terminologies (which appear in the tables) are needed. Polysemy is used in a broad sense. Specifically speaking, it refers to two senses or more of one form-such as words or phrases. Several aspects are not polysemous words. Primary refers to meanings that participants (A, B, and C) have already known. Check refers to the information source by which primary is changed into secondary. Level of difficulty is the degree of difficulty that participants decide about the secondary meaning. Correct answer refers to a teacher's (decision) of participants' answers. The relevant script is in the Appendix at the end of this paper.

\section{The First Test}

There were eight polysemous words and phrases and one non-polysemous word in Table 1. 1) get to has two meanings: arrive and meet. Based on the context, meet would is the preferred answer. Participant A used the secondary meaning arrive while $\mathrm{C}$ expressed a different meaning. Both participants still relied on context to understand the meaning of the words. In 2) go through primary meaning is experience. However participant A and B already knew the meaning but came up with a different answer. The context changed the meaning of the participants. Although the participants got the answer wrong, but we can see that context is a vital factor in interpreting the meaning. In 3), students skipped the primary meaning and had no issue finding the current secondary meaning of story.

As for 4), the basic meaning of in is container which is an extension. All three participants didn't know the meaning and came up with a different answer. Trying to image schema prepositions can cause confusions to language learners, and in most situations, prepositions causes minimal interference when understanding context. Although the participants came up with the wrong answer in 4) the participants had no issues understanding the context. Context played a large role in understanding the movie dialog. 5)'s basic meaning is picture, and it's possible to infer from the context if the suitable meaning is picture or movie. In 6), Jacks' is not a polysemous word. Considering the level of the participants' English, they should easily guess that Jacks' basic meaning is Jack's house. However, the 
participants didn't know the current answer and came up with the secondary meaning gambling place. This is an interesting case where the context actually caused students miss-interpret the sentence. Participants did not know a common U.S cultural fact that playing cards is a normal thing to do at home. In a nutshell, we can observe the fact that context has caused the participants' understanding and interpreting of meaning.

TABLE 1

Results of the First Test

\begin{tabular}{|c|c|c|c|c|c|}
\hline Polysemy & Primary & Check & Secondary & Level of difficulty & Correct answer \\
\hline \multirow[t]{3}{*}{ 1) get to } & A: arrive & con. & Unnecessary $^{2}$ & low & similar \\
\hline & B: arrive & con. & Meet & middle & right \\
\hline & C: have & con. dic. & Each & high & wrong \\
\hline \multirow[t]{3}{*}{ 2) go through } & A: experience & con. dic. & Deal with & low & wrong \\
\hline & B: experience & con. & Happen & middle & wrong \\
\hline & $\mathrm{C}$ : experience & con. dic. & Unnecessary & low & right \\
\hline \multirow[t]{3}{*}{ 3) story } & A: situation & goo. con. & What's up? & low & right \\
\hline & B: situation & con. & Unnecessary & low & right \\
\hline & $\mathrm{C}$ : situation & con. dic. & Something to talk & low & right \\
\hline \multirow[t]{3}{*}{ 4) in } & A: within & goo. dic. & No answer & high & wrong \\
\hline & B: within & inf. con. & Belong & low & wrong \\
\hline & C: within & con. dic. & Belong & middle & wrong \\
\hline \multirow[t]{3}{*}{ 5) picture } & A: photo & error & No answer & error & wrong \\
\hline & B: drawing & con. & Movie & middle & right \\
\hline & C: photo & con. dic. & Movie & middle & right \\
\hline \multirow[t]{3}{*}{ 6) Jack’s } & A: don't know ${ }^{3}$ & goo. dic. con. & Gambling & high & wrong \\
\hline & B: don't know & goo. con. & Gambling & high & wrong \\
\hline & C: don't know & con. inf. & Bar & high & wrong \\
\hline \multirow[t]{3}{*}{ 7) tied up } & A: tight & goo. dic. con. & Busy & low & right \\
\hline & B: busy & con. & Unnecessary & low & right \\
\hline & $\mathrm{C}$ : fasten & con. dic. & Busy & high & right \\
\hline \multirow[t]{3}{*}{ 8) about } & A: regarding & con. dic. & Important & low & right \\
\hline & $\mathrm{B}$ : regarding & goo. & Depend on & middle & similar \\
\hline & C: regarding & con. dic. & Important & high & right \\
\hline \multirow[t]{3}{*}{ 9) run on (ego) } & A: manage & goo. dic. con. & Important & high & similar \\
\hline & B: continue & inf. con. & Depend on & high & similar \\
\hline & C: don't know & con. dic. & Driving force & high & right \\
\hline
\end{tabular}

Note. Context $=$ con. Dictionary $=$ dic. Google $=$ goo. Inference $=$ inf. Website $=$ web.

In 7), tied up secondary meaning is busy. Participant B understood busy as the primary meaning, which we could infer that for B tie and busy are both considered as a whole in her mental lexicon. As for 8), about participants were able to distinguish between primary and secondary meaning. However, the participants relied on an information source rather than context.

All in all, whether participants successfully distinguished between the primary and secondary meanings, they were relying on the context. Context has caused negative effects in 2) and 6), while helping the participants in 8) and 9). However, context also caused confusions to the participants in 4) too. The role of the teacher is to help students understand context of the material. If so, students will be able to infer multiple meanings from the context.

\section{The Second Test}

The second test was basically not different from the first one. One remarkable difference was that the context in the first test was important for understanding the right meanings of the words or phrases. Conversely, some contexts in the second test did not work for choosing the right meanings and are discussed in the following test.

10) lead was polysemous. Participants A and C already knew two different meanings of lead. Through context, they could easily decide on an appropriate meaning. That is why they answered unnecessary in the secondary place. Level was easy for them. Participant B had one meaning for lead. When she read the relevant script, she realized that it needed a different meaning. Thus, Participant B found a relevant meaning based on the context in a bilingual

\footnotetext{
${ }^{2}$ When primary meanings are not changed, unnecessary is written in the secondary place.

${ }^{3}$ When participants do not know a word or a phrase in question, don't know or no knowledge is written in the primary place.
} 
dictionary. 11) cockamamie excuse was not polysemous. It did not require any context to understand the meaning of the phrase. Simply dictionary was enough.

12) light touch was totally new to the participants. Though it was polysemous, they did not know its polysemy at all. Through information sources, the participants discovered that it was polysemous. The problem was that they were not sure which meaning was correct in the context. They were not familiar with the relevant context, which is why it did not work here.

13) put you on is a polysemous. In this context it holds the meaning of getting a job. However, the participants answered it with a primary meaning placing it on something. But $\mathrm{B}$ and $\mathrm{C}$ were answered the correct meaning through inferring from the context, while A went too far and concluded with the meaning of tell to do. As for 15), odd was polysemous. The participants knew two senses (strange, not even number) of odd, but they did not know the third sense, which was the right meaning in the context. However, they could solve the polysemous problem, using information source which was understandable to them. 16) at sea was metaphoric rather than polysemous. Context helped the participants find the extended meaning.

To sum, in the second test, context had a major influence in determining the meanings for the participants. The meanings were not possible to infer just from an encyclopedia information. Without cultural information, participants had trouble interpreting the movie scripts, which is possible to infer that teachers need to focus on both encyclopedia and cultural information.

TABLE 2

Results of the Second Test

\begin{tabular}{|c|c|c|c|c|c|}
\hline Polysemy & Primary & Check & Secondary & Level & Answer \\
\hline \multirow[t]{3}{*}{ 10) lead } & A: main role & con. & Unnecessary & low & right \\
\hline & B: control & con. dic. & Main role & middle & right \\
\hline & $\mathrm{C}$ : main role & con. & Unnecessary & low & right \\
\hline \multirow{3}{*}{$\begin{array}{l}\text { 11) cockamamie } \\
\text { excuse }\end{array}$} & A: error & error & Error & error & wrong \\
\hline & B: don’t know & con. dic. & Ridiculous & high & right \\
\hline & C: no knowledge & dic. web. & Foolish & middle & right \\
\hline \multirow[t]{3}{*}{ 12) light touch } & A: literal mean. ${ }^{4}$ & goo. con. dic. & Friendliness & high & wrong \\
\hline & B: no knowledge & con. goo. dic. & Handle comedy & high & similar \\
\hline & $\mathrm{C}$ : literal mean. & dic. web. & Comedy & high & similar \\
\hline \multirow[t]{3}{*}{ 13) put you on } & A: place & dic. con. & Tell to do & middle & wrong \\
\hline & B: place & con. & Giving a job & high & similar \\
\hline & $\mathrm{C}:$ place & con. & Hire & low & similar \\
\hline \multirow[t]{3}{*}{ 14) come up with } & A: think of & con. & Unnecessary & low & right \\
\hline & B: think of & con. & Unnecessary & low & right \\
\hline & $\mathrm{C}$ : think of & dic. & Unnecessary & low & right \\
\hline \multirow[t]{3}{*}{ 15) odd jobs } & A: strange & dic. con. & Not regular & middle & right \\
\hline & B: strange & con. & Occasional & high & right \\
\hline & $\mathrm{C}$ : strange & dic. con. & Temporary & middle & right \\
\hline \multirow[t]{3}{*}{ 16) at sea } & A: water & con. dic. & Confused & middle & right \\
\hline & B: water & con. & Lonely & low & right \\
\hline & $\mathrm{C}$ : water & dic. & Confusion & middle & right \\
\hline
\end{tabular}

Note. Context $=$ con. Dictionary $=$ dic. Google $=$ goo. Inference $=$ inf. Website $=$ web.

\section{The Third Test}

The following Table 3 displays the test that shows what happened to the participants when they misused context. Six question items were administered in the third test. 17) managing had two different senses. One is careful expense and the other is make it. Participant $\mathrm{C}$ misjudged the context and consequently understood the meaning wrong. Although $\mathrm{C}$ misjudged the answer, he also relied on context to infer the meaning. The teacher's role in this situation is the help the students from misjudging from the context. In other words, guiding the students to interpret the right meaning from context would be the teacher's role. 18) with indicates affiliation from the context, however both A and $\mathrm{C}$ answered with the wrong answer. 19) have is a polysemous word. The basic meaning is keep and the extended meaning is invite. All three participants relied on context but produced the wrong answer. In 20), contacts was brand

\footnotetext{
${ }^{4}$ Mean $=$ meaning. Participants only knew a literal meaning of light touch.
} 
new to all the participants. The participants relied on context for meaning but participant $\mathrm{C}$ took a long time to find the relevant sense. The primary meaning was deeply entrenched in him, making it difficult for him to escape the primary meaning. Since he stuck to the primary meaning, the context did not help at first. Participant $\mathrm{C}$ made several attempts to find an appropriate sense of adhering to the context. For 20), even though the participants got the answers right, they indicated the difficulty level was different among them. For A it was easy, B and C found it difficult.

21) too deep is also a polysemous. The meaning didn't seem too difficult to the teacher, but all three participants found it hard to interpret the meaning. 22) is a polysemous. C found it easy and B said it was difficult while A said it was okay. Even though the participants got the answers right they expressed the difficulty differently in the second and third test. The point is that if the context isn't referred in a suitable way, students could find the inferring from context problematic.

TABLE 3

Results of the Third Test

\begin{tabular}{|c|c|c|c|c|c|}
\hline Polysemy & Primary & Check & Secondary & Level & Answer \\
\hline \multirow{3}{*}{ 17) managing } & A: supervise & dic. con. & Careful expense & middle & right \\
\hline & B: supervise & con. & Careful expense & middle & right \\
\hline & $\mathrm{C}$ : supervise & dic. & Make it & high & wrong \\
\hline \multirow[t]{3}{*}{ 18) with } & A: error & error & Error & error & error \\
\hline & B: together & con. & Work under & low & similar \\
\hline & C: error & error & Error & error & error \\
\hline \multirow[t]{3}{*}{ 19) have } & A: keep & con. & Invite & low & right \\
\hline & B: keep & con. & Bring & low & wrong \\
\hline & C: keep & dic. & Invite & high & right \\
\hline \multirow[t]{3}{*}{ 20) contacts } & A: touch & con. & Personal connections & low & right \\
\hline & B: touch & con. inf. & Influential people & middle & right \\
\hline & C: touch & dic. con. & Influential people & high & right \\
\hline \multirow[t]{3}{*}{ 21) too deep } & A: far downward & con. & Profound & low & right \\
\hline & B: far downward & con. & Difficult & middle & right \\
\hline & C: far downward & dic. con. & Profound & high & right \\
\hline \multirow[t]{3}{*}{ 22) boil it down to } & A: boil & con. & Summarize & middle & similar \\
\hline & B: cook & goo. con. dic. & In short & high & right \\
\hline & C: condense & dic. con. & Summarize & low & similar \\
\hline
\end{tabular}

Note. Context $=$ con. Dictionary $=$ dic. Google $=$ goo. Inference $=$ inf. Website $=$ web.

In conclusion, the first test indicated how important the context was in solving polysemous ambiguity. The second test showed that polysemous ambiguity could not be solved unless the context was fully understandable (e.g., light tough in Table 2). The third test showed some cases that misjudged the context and that made the wrong decisions to find the right senses of polysemous words or phrases.

\section{CONCLUSION AND PEDAGOGICAL IMPLICATIONS}

Since Lewis (1993), it has been acknowledged that the basis of language is lexis (Moudraia, 2001), and lexis is essential in language teaching. The primacy of meaning over grammar has also been emphasized (Nemoianu, 1994). As far as lexis is concerned, vocabulary teaching is of great importance in ESL or EFL classrooms.

Polysemous words are sometimes viewed as obstacles to enhancing vocabulary skills and are considered "highly problematic and confusing to language learners" (Veliz, 2018, p. 211). This is because one item has several related senses and also extended ones with metaphors. To overcome such problems, the current literature has borrowed insights from cognitive linguistics, which are image schemas and conceptual metaphors (Makni, 2014). The effects of applying image schemas and conceptual metaphors to ESL or EFL classrooms have been well published (Makni, 2014; Mitsugi, 2013, 2017). These studies have already achieved theoretical status. However, image schemas and conceptual metaphors seem to be natural properties of language users. ESL or EFL teachers do not have to use such concepts in their classrooms because they naturally emerge in everyday conversations, resulting in polysemy.

In this paper, we observed how participants would handle related senses of polysemous words and phrases without teaching image schemas and conceptual metaphors. The participants were administered three tests. As mentioned in 
Section 4, the participants successfully used the context to handle polysemous words and phrases. In the second test, the context did not work well in some polysemous phrases because the context was not based on stable information, such as cultural knowledge. The third test showed that the participants made mistakes because they misjudged the context. From these tests, it was discovered that participants interpreted vocabulary mainly based on the context. Thus, ESL or EFL teachers should focus on helping their students understand texts. This kind of instruction will lead the students to build a convincing context, allowing them to confidently interpret polysemous words or phrases correctly.

Furthermore, polysemous words are not issues for L2 learners to comprehend. Rather it's in the students inborn nature to learn from context of the target text. EFL teachers might as well build context for their students in that the students tend to use context mainly and they solve the polysemy ambiguity with the help of context.

\section{REFERENCES}

Abou-Khalil, V., Helou, S., Flanagan, B., Chen, M. R. A., \& Ogata, H. (2019). Learning isolated polysemous words: Identifying the intended meaning of language learners in informal ubiquitous language learning environments. Smart Learning Environments, 6(13). https://doi.org/10.1186/s40561-019-0095-0

Allen, W. (Director). (2016). Café society [Motion picture]. United States: Gravier Productions.

Bielak, J. (2011). Cognitive linguistics and foreign language pedagogy: An overview of recent trends and developments. In M. Pawlak (Ed.), Extending the boundaries of research on second language learning and teaching (pp. 241-261). Berlin, Germany: Springer. https://doi.org/10.1007/978-3-642-20141-7_19

Boers, F. (2013). Cognitive linguistic approaches to teaching vocabulary: Assessment and integration. Language Teaching, 46(2), 208-224. https://doi.org/10.1017/S0261444811000450

Croft, W., \& Cruse, D. A. (2004). Cognitive linguistics. Cambridge, UK: Cambridge University Press. https://doi.org/10.1017/CBO9780511803864

Csábi, S. (2004). A cognitive linguistic view of polysemy in English and its implications for teaching. In M. A. S. Niemeier (Ed.), Cognitive linguistics, second language acquisition and foreign language teaching (pp. 233256). Berlin, Germany: De Gruyter Mouton.

Cuyckens, H., \& Zawada, B. (1997). Introduction. In H. Cuyckens \& B. Zawada (Eds.), Polysemy in cognitive linguistics: Selected papers from the fifth international cognitive linguistics conference (pp. ix-xxvii). Amsterdam, The Netherlands: John Benjamins.

Daiu, S. (2015). The main features of semantic approach of polysemy. Journal of Educational and Social Research, 5(3), 169-173. https://doi.org/10.5901/jesr.2015.v5n3p169

Evans, V., \& Green, M. (2006). Cognitive linguistics: An introduction. Edinburgh, UK: Edinburgh University Press.

Evans, V., \& Tyler, A. (2005). Applying cognitive linguistics to pedagogical grammar: The English preposition of verticality. Revista Brasileira de Linguistica Aplicada, 5(2), 11-42. https://doi.org/10.1590/s198463982005000200002

Falkum, I. L. (2009). A pragmatic solution to the polysemy paradox. UCL working papers in linguistics, 21, 27-54.

Falkum, I. L. (2011). The semantics and pragmatics of polysemy: A relevance-theoretic account (Doctoral dissertation, University College London, London, England). Retrieved from https://discovery.ucl.ac.uk/id/eprint/1139079/

Falkum, I. L. (2015). The how and why of polysemy: A pragmatic account. Lingua, 157, 83-99. https://doi.org/10.1016/j.lingua.2014.11.004

Falkum, I. L., \& Vicente, A. (2015). Polysemy: Current perspectives and approaches. Lingua, 157, 1-16. https://doi.org/10.1016/j.lingua.2015.02.002

Faniran, K. F. (2016). A critical study of polysemy: A perspective of French language and its parts of speech. International Journal of Advanced Academic Research/Arts, Humanities \& Education, 2(7), 7-18.

Goldenberg, E. R. (2015). The role of context in early language development (Doctoral dissertation, University of California, Los Angeles). Retrieved from https:/escholarship.org/uc/item/7bf9r1fg

Gries, S. Th. (2015). Polysemy. In E. Dabrowska \& D. Divjak (Eds.), Handbook of cognitive linguistics (pp. 472490). Berlin, Germany: De Gruyter Mouton. https://doi.org/10.1515/9783110292022-023 
Hoff, E. (2006). How social contexts support and shape language development. Developmental Review, 26(1), 55-88. https://doi.org/10.1016/j.dr.2005.11.002

Holme, R. (2012). Cognitive linguistics and the second language classroom. TESOL Quarterly, 46(1), 6-29. https://doi.org/10.1002/tesq.5

Jager, B., \& Cleland, A. A. (2016). Polysemy advantage with abstract but not concrete words. Journal of Psycholinguistic Research, 45(1), 143-156. https://doi.org/10.1007/s10936-014-9337-z

Ki, H. Y., \& Shin, K. S. (2020). Emotion analysis using a bidirectional LSTM for word sense disambiguation. The Journal of Bigdata, 5(1), 197-208. https://doi.org/10.36498/kbigdt.2020.5.1.197

Kovács, É. (2011). Polysemy in traditional vs. cognitive linguistics. Eger Journal of English Studies, 11, 3-19.

Kovács, É. (2013). The role of context in polysemy. Romanian Journal of English Studies, 9(1), 60-69. https://doi.org/10.2478/v10319-012-0007-x

Lakoff, G. (1987). Women, fire, and dangerous things: What categories reveal about the mind. Chicago, IL: The University of Chicago Press.

Lakoff, G., \& Johnson, M. (1980). Metaphors we live by. Chicago, IL: University of Chicago Press.

Langacker, R. W. (1987). Foundations of cognitive grammar, vol. 1: Theoretical prerequisites. Stanford, CA: Stanford University Press.

Langacker, R. W. (1988). Review of George Lakoff: Women, fire, and dangerous things: What categories reveal about the mind. Language, 64(2), 384-395. https://doi.org/10.2307/415440

Lewis, M. (1993). The lexical approach. Hove, UK: Language Teaching Publications.

Littlemore, J. (2009). Applying cognitive linguistics to second language learning and teaching. New York, NY: Palgrave Macmillan. https://doi.org/10.1057/9780230245259

Littlemore, J., \& Juchem-Grundmann, C. (2010). Introduction to the interplay between cognitive linguistics and second language learning and teaching. AILA Review, 23(1), 1-6. https://doi.org/10.1075/aila.23.01 lit

Makni, F. (2014). Applying cognitive linguistics to teaching polysemous vocabulary. Arab World English Journal, $5(1), 4-20$.

Matsumoto, N. (2006). Applying cognitive grammar to pedagogical grammar: The case of "To". In M. Nakano \& J, Park (Eds.), Proceedings of the $11^{\text {th }}$ Conference of Pan-Pacific Association of Applied Linguistics (pp. 116130). Kangwon: Pan-Pacific Association of Applied Linguistics http://www.paaljapan.org/resources/proceedings/PAAL11/pdfs/10.pdf

Mitsugi, M. (2013). The effectiveness of core meaning based instruction on preposition choice. Research Bulletin of English Teaching, 10, 1-25.

Mitsugi, M. (2017). Schema-based instruction on learning English polysemous words: Effects of instruction and learners' perceptions on the instruction. Journal of Pan-Pacific Association of Applied Linguistics, 21(1), 2143.

Moudraia, O. (2001). Lexical approach to second language teaching. ERIC digest. Washington, DC: ERIC Clearinghouse on Languages and Linguistics. (ERIC Document Reproduction Service No. ED455698). Retrieved from https://files.eric.ed.gov/fulltext/ED455698.pdf

Nemoianu, A. M. (1994). [Review of the book The lexical approach, by M. Lewis]. TESL-EJ, 1(2). Retrieved from https://www.tesl-ej.org/wordpress/issues/volume1/ej02/ej02r3/

Nerlich, B. (2003). Polysemy: Past and present. In B. Nerlich, Z. Todd, V. Herman, \& D. D. Clarke (Eds.), Polysemy: Flexible patterns of meaning in mind and language (pp. 49-76). Berlin, Germany: De Gruyter Mouton. https://doi.org/10.1515/9783110895698.49

Polysemy and Context. Types of Context. (n.d.). Retrieved from https://thelib.info/tehnologii/3050276-polysemyand-context-types-of-context/

Ravin, Y., \& Leacock, C. (2000). Polysemy: Overview. In Y. Ravin \& C. Leacock (Eds.), Polysemy: Theoretical and computational approaches (pp. 1-29). Oxford, UK: Oxford University Press.

Rowe, M. L., \& Weisleder, A. (2020). Language development in context. Annual Review of Developmental Psychology, 2, 201-223. https://doi.org/10.1146/annurev-devpsych-042220-121816

Sennet, A. (2016). Polysemy. Oxford Handbooks Online. https://doi.org/10.1093/oxfordhb/9780199935314.013.32 
Selivan, L. (2018). Lexical grammar: Activities for teaching chunks and exploring patterns. Cambridge, UK: Cambridge University Press.

Taylor, J. R. (2002). Cognitive grammar. Oxford, UK: Oxford University.

Tremblay, C., Macoir, J., Langlois, M., \& Monetta, L. (2014). The role of polysemy on metaphor comprehension processing: The example of Parkinson's disease. Journal of Neurolinguistics, 30, 1-13. https://doi.org/10.1016/j.jneuroling.2014.02.002

Tyler, A., Mueller, C., \& Ho, V. (2011). Applying cognitive linguistics to learning the semantics of English to, for, and at: An experimental investigation. Vigo International Journal of Applied Linguistics, 8(1), 181-205.

Ullmann, S. (1959). The principles of semantics: A linguistic approach to meaning. Oxford, UK: Blackwell.

Vardidze, T. (2020). The impact of teaching English polysemy through similarity-based approach. Journal of Education in Black Sea Region, 5(2), 112-125. https://doi.org/10.31578/jebs.5i2.205

Veliz, L. (2018). A route to the teaching of polysemous lexicon: Benefits from cognitive linguistics and conceptual metaphor theory. International Journal of Applied Linguistics \& English Literature, 7(1), 211-217. https://doi.org/10.7575/aiac.ijalel.v.7n.1p.211

Vicente, A., \& Falkum, I. (2017). Polysemy. Oxford Research Encyclopedia of Linguistics. https://doi.org/10.1093/acrefore/9780199384655.013.325

Wei, X., \& Lou, Y. (2015). A study of word meaning acquisition of polysemous words for English majors. Creative Education, 6, 1993-2001. https://doi.org/10.4236/ce.2015.618204

Willis, D. (1990). The lexical syllabus: The lexical approach to language teaching. London, UK: Collins.

\section{APPENDIX 1}

The First Test Dialogue

Phil: Come in. Come in. Sorry I've been so hard to get to. Hate to tell you what I've been going through with this Howard Hawks thing in Chicago.

Bobby: Oh! That's okay, Uncle Phil.

Phil: Sit. So... what's the story? Uh, Rose tells me you wanna live out here?

Bobby: Yes... I... I could not go on in my father's business. Sorry... It was, it was stultifying, I wanna do something more interesting with my life.

(The intercom is ringing.)

Secretary: Call for you, sir.

Phil: (to Bobby) Hold on. (on the phone) Hello? Yeah, hi Paul. Yeah, it's a mess down there. Adolphe Menjou is threatening to walk off the picture. I'll give you the details at Jack's, Friday. You will be at the poker game, right? Alright, we'll talk then. Yep, yep. I'm tied up right now. Great.

(Their conversation resumes.)

Phil: You can't believe the last couple of weeks. Oh, Christ Ben! It's all about ego! This whole town runs on ego.

\section{APPENDIX 2}

The Second Test Dialogue

(The intercom is ringing again.)

Secretary: RKO calling...

Phil: (to Bobby) Hold on... (on the phone) Hello? Oh, Jesus! What...? Absolutely. Yes. Lunch on Friday at the Brown Derby. Yeah. And bring Harry because I agree Joel McCrea would be the perfect to play the lead. Absolutely. See you Friday. And don't disappoint me by canceling with some cockamamie excuse.

(Their conversation resume again.)

Phil: (to Bobby) What do you think of Joel McCrea?

Bobby: Oh, um $\cdots$ I think he's a great movie star.

Phil: What I like about Joel is that he can play drama and give you the light touch. Great range. So... what are, what are your plans? Are you plannin' on staying out here?

Bobby: Well, I thought maybe if you know of something I can get started with out here, maybe, something at your agency? Phil: Here, like what?

Bobby: I don't know just something so I can stay out here. I kind of, I kind of need a job.

Phil: There's nothing here at the moment, I mean if you're talking about the mail room.

Bobby: The mail room, yeah so that's... Yeah, sure, maybe to be $\cdots$ begin with. The mail room $\cdots$

Phil: If something comes up in the mail room, I could let you know. 
Bobby: OK yeah, so I mean there nothing here, now then?

Phil: Unless... I put you on working for me. Come up with some cockamamie title. I always have some errands to run. Bobby: Oh! I'll do anything.

Phil: You know anybody in town?

Bobby: No. I don't.

Phil: Hotel life, the worst, right? Umm, Karen and I will invite you over for dinner. And we've these parties. Sunday brunches. We'll invite you. You'll meet some nice people.

Phil: (on intercom) Vonnie, come in here. Can you? (to Bobby) Check in with me each day and I will have some odd jobs for you to do.

Bobby: This is so nice of you, Uncle Phil.

(Vonnie enters.)

Phil: (to Bobby) Stop with The Uncle. It's Phil. We don't wanna over-emphasize the nepotism. (to Vonnie) Vonnie, this is my nephew... Umm...Bobby. Bobby... Bobby. He just moved out here. Maybe you can help get him oriented. Show him the town? Right now, he's at sea.

\section{APPENDIX 3}

The Third Test Dialogue

(Cut to a letter to Evelyn.)

Bobby's voice: Dear Evelyn, just a note to say hello. I'd call more frequently but between mom and dad, you and Ben, the long-distance calls are probably bankrupting everybody. Ben sent me a few bucks, so I'm managing. I gotta job with Uncle Phil. Not much of a job, but he's going to have me to dinner and his brunches and will introduce me to some contacts. His secretary is going to show me around, this weekend. She is very pretty.

(Cut to a letter to Bobby.)

Evelyn's voice: Dear Bobby, it's raining here today. Very pretty, but a bit melancholy. Leonard says, it's the poignancy of life, and not only do we have to embrace its meaninglessness, but celebrate life because it has no meaning. It's too deep for me, but mom always boils it down to: Live every day like it's your last. And someday you will be right. 